\title{
Taking a Transcendental Stance: Anti-Representationalism and Direct Realism in Kant and Husserl
}

\author{
Julia Jansen
}

So much effort has gone into dusting Husserl off in order to make him fit for contemporary debate. Specifically, the dust of classical German philosophy- idealism' for short - had to come off. Kantian dust was particularly irritating because it drew attention to Husserl's transcendental idealism, which was unfashionableeven amongst Husserlians - from its inception. A good look at both Kant and Husserl, however, shows that this is nothing to fear. If anything, a comparison with Kant bolsters Husserl's realism, helps one understand the distinctiveness of his transcendental idealism, and highlights Husserl's methodological commitment to the sole justificatory power of phenomenological evidence.

In this article I initially focus on just one aspect of the complex systematic relation between Kant and Husserl: their notions of sensible representation (sinnliche Vorstellung). In my reading, I agree with realist interpretations of Kant and Husserl, which have been put forward against charges of representationalism in both fields independently from each other. By 'representationalism', I mean the construal of mind-world relations as relations between internal representations to external objects (Ameriks, 2000; Rockmore, 2007). ${ }^{1}$ In a second section, I argue that the realism implied by Kant's and Husserl's anti-representationalism should not surprise us but rather be expected as integral to the project of transcendental idealism. Obviously, the real task is to provide a coherent and comprehensive understanding of transcendental idealism in both Kant and Husserl given their strong realism. My task in this paper is a smaller one, namely to clarify those aspects of their transcendental idealisms that are directly relevant to their accounts of (sensible) representation.

\footnotetext{
1 'Representationalism' as I refer to it here is closely related to more specific theories that also think of object reference as an indirect process mediated by representations of some sort, such as phenomenalism and sense data realism. Other senses of 'representationalism' are in circulation, both in philosophy of mind and in the cognitive sciences, but those are not considered here.
}

\footnotetext{
J. Jansen $(\bowtie)$

Department of Philosophy, University College Cork, 4 Elderwood College Rd,

Cork, Ireland

E-Mail: julia.a.jansen@gmail.com

F. Fabbianelli, S. Luft (Hrsg.), Husserl und die klassische deutsche Philosophie,

Phaenomenologica, DOI 10.1007/978-3-319-01710-5 6,

(C) Springer International Publishing Switzerland 2014
} 


\section{Representations and Representationalism in Kant and Husserl}

Any innocent use of the term 'representation' is no longer possible insofar the issue of 'representationalism' (or its younger cousin, 'internalism') is immediately raised along with it. Both Kant and Husserl are obviously representationalists in the trivial sense that they use the notion of 'representation (Vorstellung)'. In the less trivial, but still very broad sense, they both believe that there is no access or knowledge of the world as it is 'in itself', independent from how it can be experienced, or 'represented' (although their interpretations of this claim diverge significantly from each other). The question is whether this makes them advocates of representationalism in the substantive sense that is at issue here, namely the position that access to external objects is at best indirect, mediated by internal representations. Because contemporary debates surrounding anti-representationalism mainly concern perception, what is required for settling this question is a proper understanding of Kant's and Husserl's notions of sensible (sinnliche) or intuitive (anschauliche) representation. ${ }^{2}$

\subsection{Kant's Anti-representationalist Notion of Sensible Representation}

'Representation', the most basic term in Kant's transcendental philosophy, was, under the name 'idea', one of the most central notions of seventieth and eightieth century philosophical discourse. By the time Kant was developing his own account, the notion that the mind related to the world indirectly, through a 'veil of ideas' (if at all), and the particular conception of ideas as images held considerable ground in both rationalist and empiricist quarters - not only in Britain but also in Germany. Kant's redefinition of an 'idea' as a concept "surpassing the possibility of experience" (KrV, A 320/B 377), and thus as being nothing like an image, must therefore be understood as part of Kant's break with the standard view of his time.

Kant preserves the generic sense of the term 'idea' in the equally generic term 'representation', but denies that sensible representations are, or are like, images (Bilder). Instead, Kant describes them as 'intuitions (Anschauungen)'. Far from being a terminological quibble, Kant's rejection of any 'image theory' and his introduction of a theory of intuitions again marks his departure from both German and British 'ways of ideas' in at least two important respects. First, the equation of sensible representations with images strongly encourages the view that they are passively received, so to speak 'ready-made'. Kant, however, maintains that intuitions are generated in complex syntheses, and hence require an active mind. Second, it strongly encourages the view that they replace external objects as direct objects of

\footnotetext{
${ }^{2}$ Neither Kant nor Husserl simply equates sensible or intuitive representation with perception. This can get lost in translation when one considers them in the context of contemporary debates, which are usually concerned with perception in particular.
} 
awareness. Kant, on the contrary, maintains that intuitions constitute an immediate reference to the objects given in them.

In the Critique of Pure Reason one thus finds close to no references to images. Perhaps the most famous exception is the passage in the Transcendental Deduction of the first edition, where Kant argues for the claim that intuitions are not passively received but actively synthesized by the mind. By 'perceptions (Wahrnehmungen)' Kant here means 'conscious intuitions':

But because every appearance contains a manifold, so that different perceptions are in themselves encountered in the mind sporadically and individually, these perceptions need to be given a combination that in sense itself they cannot have. Hence there is in us an active power to synthesize this manifold. This power we call imagination [...]. For the imagination is to bring the manifold of intuition into one image [...]. (KrV, A 120)

In the footnote to this passage, Kant underscores his sweeping criticism of the available theories of perception,

[...] partly because this power (i.e., the imagination) has been limited [...] to reproduction only, and partly because they believed that the senses not only supply us with impressions, but indeed also assemble these impressions and thus bring about images of objects. (KrV, A 120 n.)

Kant uses the term 'image' in order to indicate those theories of perception that fail. The degree to which he is committed to a non-imagistic account of intuition is impressively illustrated by the vehemence with which he reacts against his critic Johann A. Eberhard:

Where have I ever called intuitions of space and time (which first of all make images possible) themselves images [...]? He [Eberhard] has so internalized the deceptive automatism of using the expression pictorial [bildlich] instead of sensible [sinnlich] that it always remains with him. (Ak, 8, p. 222)

For Kant, sensibility is not a purely passive readiness to receive images through the senses, but includes, under the name of the power of the imagination (Einbildungs$k r a f t$ ), the active capacity to take up and synthesize incoming sense data. ${ }^{3}$ Intuitions are the products of such syntheses, which, unlike images, are characterized by the immediacy with which they refer "directly to the object" (KrV, A 320/B 377; cf. A 19/B 33 and passim). As the German term literally says, an intuition is not 'something looked at' ('etwas Angeschautes'), but constitutes a 'looking at' ('eine Anschauung'), namely a 'looking at' an object. ${ }^{4}$

And yet, the view that intuitions are themselves products of (mental) syntheses appears to confirm, even radicalize, a representationalist reading of Kant insofar as it has been taken to suggest a constructivist position. ${ }^{5}$ However, the use of the term

\footnotetext{
${ }^{3}$ Kant assigns this synthesis to the imagination although he attributes its transcendentality to an 'effect of the understanding' on inner sense ( $\mathrm{KrV}, \mathrm{B} 152)$.

${ }^{4}$ This is obviously not meant to suggest that every intuition is a veridical perception of a real object. Whether the object presented in intuition is real, is a matter of judgment for Kant, and an intuition need not be a perception but could, for exemple, be an imagination, hallucination, etc.

${ }^{5}$ Tom Rockmore, for example, speaks of Kant's 'constructivism', namely "the view that a necessary condition of knowledge is that the knower construct, constitute, make, or produce its cognitive object" (Rockmore, 2007, p. 9).
} 
'constructivism' is problematic - above all because it invites confusion between empirical and transcendental senses of synthesis. An empirical misunderstanding of the transcendental synthesis easily leads to a representationalist view which Kant does not adopt. However, due to this misunderstanding, this view has long been considered the standard interpretation, and still finds powerful advocates today. This view involves the idea that intuitions (often considered as 'raw' sense data) are, in a first step of passive reception, given in a purely spatial and temporal order (whatever that may be), and then, in a second step of construction, subjected to the categories. ${ }^{6}$ Such an empirical doctrine of representations simply cannot capture the upshot of Kant's transcendental account that considers a representation not only as something one apprehends (as itself an object of inner sense) but something in virtue of which one apprehends an object (of outer sense). The whole point of Kant's notion of a transcendental synthesis of the imagination-understood as an influence of the understanding on inner sense - is to explain the necessity of what in experience is only observable as a contingent fact: that in conscious intuitions we are always given objects (or, to be more precise, we are always given undetermined appearances that are determinable in judgments as objects), and not mere sensations.

Moreover, the very plausibility of such an empirical doctrine of representations is itself largely based on a further confusion of empirical and transcendental levels of analysis. It 'naturally' follows from an empirical reading of claims repeatedly made by Kant, that appearances are 'mere representations' and, as such, 'in us'. In the empirical sense of the expression, this would distinguish things 'in us' (understood as internal representations) from things 'outside us' (understood as external objects). However, in Kant's transcendental sense of the expression, it distinguishes things not distinct from us (and our ways of cognizing them) from things distinct from us (and our ways of cognizing them); that is, it distinguishes things as appearances from things in themselves (cf. Allison, 2004; Allais, 2011, p. 384). I say more about the impact of this distinction on Kant's notion of realism below, but its impact on Kant's anti-representationalist theory of intuitions is already clear: Due to Kant's distinction between the empirical and the transcendental senses of the expression, it holds without contradiction that objects of outer sense

\footnotetext{
${ }^{6}$ This is, of course, not to deny that intuition "takes place only insofar as the object is given to us" and that this "is possible only [...] by the mind's being affected in a certain manner" (KrV, A 19/B 33). It is just to make the point that, for Kant, the mind's sensibility is not merely passive but in virtue of the imagination also spontaneous. Contrary to representationalisms that, as Rorty (1979) famously put it, consider the mind's sensibility a passive 'mirror of nature', Kant's transcendental idealism involves the claim that the way objects are given to us in intuition is already under the "effect of the understanding" (Rorty, of course, misses that both Kant and Husserl reject a 'mirroring' representationalism.) To call the synthesis of the imagination that is the "first application" (KrV, B 152) of the understanding's effect on sensibility "transcendental" is also to say that the mind does not, in a first step, merely receive sensations, and then, in a second step, empirically synthesize them into intuitions. The same empirical fallacy is committed by interpretations that locate the second step not in the imagination but in judgement (for the most recent attempt see Abela, 2002). It is committed by any interpretation that involves a theory of two steps and thus turns Kant's transcendental theory into the description of an empirical process.
} 
are both (empirically) 'outside us' and (transcendentally) 'in us', i.e., they are both external and mind-dependent.

In conclusion, intuitions are, as Derk Pereboom puts it, "immediate awarenesses" of objects (Pereboom, 1988, pp. 326, 338). This holds both for empirical intuitions, which are our immediate awarenesses of empirical objects (of outer or inner sense), and for pure intuitions, which are our immediate awarenesses of formal objects (of space or time as objects). The fact that Kant is still accused of advancing a representationalist theory of representations betrays the force the post-Cartesian legacy of the 'way of ideas' continues to hold over debates in philosophy of mind, consciousness and cognition more generally. It is also symptomatic of a persisting confusion of empirical and transcendental levels of analysis, which continues to obscure the radicality with which Kant reconfigured the post-Cartesian philosophical landscape once and for all.

\subsection{Husserl's Anti-representationalist Notion of Representation}

At the time when Husserl began to form his phenomenological critique of cognition, it was, despite the collapse of German idealism, still de rigueur to phrase issues in terms of representations (Vorstellungen). The language of representations was Bernard Bolzano's, Wilhelm Wundt's, Franz Brentano's and Carl Stumpf's language. It was, of course, the language of Neo-Kantianism, but, due to the translation of 'idea' as 'Vorstellung', it was also the (German) language of British empiricism. Amongst all the influences that had an impact on Husserl, Brentano was, at least initially, the strongest. In opposition to "Kant's decadent position" (Körner, 1987, p. 11), Brentano advocated a return to pre-Kantian (Aristotelian, Scholastic and Cartesian) notions of representation. This set the scene for Husserl, and probably goes some way in explaining why he had to fight the same battles against representationalism as Kant had two hundred years earlier.

Despite the ubiquity of 'representation' in the philosophical and psychological discourse of his day, Husserl observed the lack of consensus in its use and meaning. In the Logical Investigations, Husserl counts no less than thirteen different senses of 'representation' (5th Inv., § 44). His is a very broad understanding of the term; all consciousness is a case of 'representing' (Vorstellen) (2nd Inv., § 23). Consciousness in its broadest sense, he writes, is "a comprehensive designation for "mental acts', or 'intentional experiences [Erlebnisse]", i.e., representations, "of all sorts" (5th Inv.: Hua XIX/1, $\S 1$, p. 356). However, by characterizing representations as 'lived through (erlebte)' acts of consciousness, Husserl rejects Brentano's and, for that matter, any other notion of representations as 'internal objects' or 'psychological entities'. In opposition to such theories, Husserl considers representations as modes of being conscious of something, i.e., as modes of intentionality (for example, 'perceptual representation' is 'perceptual consciousness', 'phantasy representation (Phantasievorstellung)' is 'phantasy consciousness', etc.). In short, even for the early Husserl, having a representation of a particular kind (e.g., an intuitive representation) is being conscious of an object in a particular mode (e.g., intuitively). 
With his distinction between intuitive presentations and signitive (or symbolic) representations, Husserl reappropriates the Kantian distinction between intuitions and concepts. Intuitive representations are sensory or quasi-sensory representations, e.g, perceptions, memories, phantasies. Having intuitive representations means intuiting (e.g., seeing, touching, hearing, etc.) objects in their spatio-temporal specifications and with their determining sensible (visual, haptic, audial etc.) features. Husserl, like Kant, considers them immediate, albeit not necessarily veridical, awarenesses of actual objects, which are thus given 'in the flesh' or 'in person'.7 Intuitions, in this sense, are thus precisely not internal objects that mediate our experience of the world. Rather, they are our experiences of external, or, in Husserl's language, 'transcendent' objects, i.e., of objects that are different from us and our mental states. Accordingly, already in the Logical Investigations Husserl forcefully condemns the theory of internal objects as "one of the worst conceptual distortions known to philosophy" which "is without doubt responsible for an untold legion of epistemological and psychological errors" (2nd Inv.: Hua XIX/1, § 23, p. 170). In an appendix to the fifth Investigation, which is unambiguously entitled "Critique of the 'image theory' and of the doctrine of the 'immanent' objects of acts", Husserl makes it perfectly clear "that the intentional object of a representation is the same as its actual object, and on occasion as its external object, and that it is absurd to distinguish between them." (5th Inv., Appendix to $\S 11$ and $\S 20$ : Hua XIX/1, p. 439).

In Husserl's view, as long as "one deals with mental processes as 'contents' or as psychical 'elements' which are still regarded as bits of things [Sächelchen]" (Ideas I: Hua III $/ 1, \S 112$, p. 253), no progress towards an adequate theory of consciousness can be made. Thus Husserl (like Kant) rejects an empirical doctrine of representations and considers a representation not as something one apprehends (as itself an object, a 'Sächelchen'), but as something in virtue of which one apprehends an object. In Ideas $I$, in the context of an explicitly transcendental analysis, Husserl speaks of a relation between 'transcendental' (i.e., constituting) consciousness and a 'transcendent' (i.e., constituted) object. In the case of perceptual consciousness, Husserl claims, this object is nothing other than the 'physical thing' perceived, which simply "cannot be given in any possible perception as something really [reell] inherently immanent," but is "in itself, unqualifiedly transcendent" (Hua III/1, § 42, p. 87). Again, Husserl (like Kant) rejects an empirical idea of perceptual objects as 'mere representations' as 'really inherently immanent' ('in us'). In his transcendental sense of the expression, 'intentional objects' refers to things that are not distinct from us (and our ways of cognizing them); that is, it refers to transcendent things insofar as they stand in a relation to consciousness.

With his transcendental standpoint in place, Husserl begins to avoid the term 'representation', which is so difficult to divest of empirical confusions, and replaces it with a pair of technical terms that are meant to capture both the subjective and the objective moments of intentionality: 'noesis' (the act of intention) and 'noema'

\footnotetext{
${ }^{7}$ Image-consciousness (Bildbewusstsein) is the exception because it, unlike perception and other intuitive representations, is, as the title already indicates, mediated by an image. Husserl's anti-representationalist account is in part driven by the contrast with image-consciousness, which Husserl began working on in the late 1890ies (Hua XXIII).
} 
(the object as it is intended). And yet, the noema, no less than the old-fashioned 'representation', has motivated representationalist interpretations. The contentious issue is Husserl's distinction between the noema and the intended object. In Ideas I he famously writes:

The tree simpliciter, the thing in nature, could not be more different from the perceived tree as such that, as perceptual sense, inseparably belongs to the perception. The tree simpliciter can burn down, can be reduced to its chemical elements, etc. But the sense - the sense of this perception, something that necessarily belongs to its essential being - can not burn down. (Hua III/1, § 89, p. 205)

Husserl thereby returns to a distinction that he already makes in the Logical Investigations, namely a distinction "between the object tout court [schlechthin], which is intended on a given occasion, and the object as it is then intended" (5th Inv.: Hua $\mathrm{XIX} / 1, \S 17$, p. 414). This distinction is often interpreted as a clear expression of Husserl's representationalism because it appears to posit the noema as a third entity between consciousness and the 'object tout court'. However, the following passage can also be found in Ideas I:

I perceive the physical thing, the Object belonging to Nature, the tree there in the garden; that and nothing else is the actual Object of the perceptual 'intention.' A second immanental tree, or even an 'internal image' of the actual tree standing out there before me, is in no way given, and to suppose that hypothetically leads to an absurdity. (Hua III/1, § 90, pp. 207-208)

Here Husserl affirms the identity of the noema with the intended object - a view that can be described as anti-representationalist in the sense in which I have been using it.

The apparent conflict between the two passages is again due to a confusion of empirical and transcendental levels of analysis. ${ }^{8}$ When Husserl speaks of an inflammable 'tree simpliciter' and opposes it to the non-inflammable 'sense' of its perception, he makes the empirical distinction between a 'thing in itself', i.e., a thing considered independently from its appearance to a consciousness, and an 'intentional object', i.e., a thing considered in its relation to consciousness (in the 'sense' it has for consciousness). In transcendental analysis, however, the object of analysis is not the tree as physical thing but the same tree as an object for consciousness. Its transcendental analysis does not say anything about its physical properties (e.g., whether it is inflammable or not), but investigates the tree as it is given in conscious experience (the tree as noema). This neither denies the existence of the physical tree nor posits the existence of the noema as a new third 'intensional' entity between consciousness and object. It simply clarifies the complexity of what, in natural analysis, we consider 'ordinary perception'.

There is, then, also a transcendental-phenomenological sense of a 'thing itself'. Any perception of a real tree includes both the awareness of different profiles of the tree (due to different angles, different lighting conditions, etc.) and, at the same time, the awareness of these different profiles as different profiles of the same tree, which

\footnotetext{
${ }^{8}$ This confusion also results in the conflicting 'East Coast' and 'West Coast' interpretations of the noema; the former is a transcendental, the latter is an empirical reading.
} 
is thus irreducible to any specific sense in which it is presented and thus 'transcendent' in the Husserlian sense. This complex experience of the tree, however, does not require an internal representation of the tree. The tree, as we experience it (the noema), is the same tree that we experience (the physical thing). As Sartre reminds us, Husserl does not think that this experience is 'in consciousness', but that we experience the tree "just where it is: at the side of the road, in the midst of the dust" (Sartre, 2002, p. 382). To construe perception as a case in which a noema is, so to speak, entertained while its reference is yet to be established is to commit not only "a mentalistic misinterpretation of the phenomenological dimension", which misinterprets noemata "as part of the mental inventory" (Zahavi, 2004, p. 58), it is also to commit an empirical misinterpretation of a transcendental analysis, which misinterprets noemata as part of an empirical theory.

\section{Direct Realism in Kant and Husserl: Some Essential Agreements and Disagreements}

My claim that Kant and Husserl are anti-representationalists about sensible representation commits both of them to the view that cognition is, in virtue of these representations, immediately related to objects, which are not themselves mere representations but, in a sense to be qualified, mind-independent. This reference to mind-independent objects constitutes the direct realism I thereby attribute to both of them. However, direct realism is usually understood - under the name of 'naïve realism' - as a purely empirical, even commonsensical view, which, for Husserl, is characteristic of the 'natural attitude'. Clearly, neither Kant nor Husserl was a naïve realist. On the contrary, they both regarded themselves as transcendental idealists. Hence, an anti-representationalist interpretation must show how it is compatible with their respective accounts of transcendental idealism, which is usually understood as the thesis that we only know objects as they appear to us, and not as they are in themselves. This claim is often used interchangeably with yet another one, namely that there are 'for us' no mind-independent objects but only appearances.

Kant's project of transcendental idealism was already suspected of being an ordinary idealism in new clothes before it could even get off the ground. The same suspicion now persists after more than two hundred years of scholarship, which has led Karl Ameriks to refer to it as "a stray dog that refuses to go home" (Ameriks, 1996, p. 67). Husserl's transcendental idealism has fared no better. Many of Husserl's contemporary followers saw in his 'dipping into idealism' enough of a reason to turn away from their master. This disappointment lingers, as is evident from recent demands for a final "break with any transcendental scheme" (Romano, 2012, p. 444; Romano, 2011, 19 f.). In a manner of speaking, there are thus two dogs on the loose, and it might prove more effective to pursue them together than in isolation, especially because the lack of clarity regarding their relation tends to make it even more difficult to catch them. I contribute to this greater end in a small way 
by focusing on direct implications of the anti-representationalist views I attribute to both Kant and Husserl.

\subsection{Some Essential Agreements Concerning Transcendental Idealism}

The most important agreement between Kant and Husserl is also what sets them apart from all other direct realists, both past and present, who fail to make a critical problem of their position, a problem whose explanation or clarification must be philosophical, and not empirical, because any empirical explanation would have to rely on the very realism it is meant to explain or clarify. ${ }^{9}$ Since 'philosophical' is here opposed to 'empirical' or 'natural', this implies that the explanation or clarification sought must be in some sense a priori (which can be interpreted in different ways, e.g., as formal, material, ontological, or historical). I take it that this constitutes the 'transcendental stance' in its most general form (which need not be Kantian or Husserlian), ${ }^{10}$ and that it necessarily involves realism as its explanandum. ${ }^{11}$

However, while this 'transcendental stance' is, if I am right, a necessary characteristic of Kantian and Husserlian philosophy, neither Kant nor Husserl are simply 'transcendentalists', they are also idealists. Since 'ideal' is here opposed to 'real' in the broad sense of 'objective', this implies that they are committed to seeking the philosophical explanations or clarifications for their realist positions in ideal conditions, where 'ideal' means, broadly speaking, 'subjective' (which can be interpreted in different ways, e.g., as mental, psychological, formal, or phenomenological). I take it that this constitutes idealism in its most general form (which need not be Kantian or Husserlian), ${ }^{12}$ and that it necessarily involves the reference to some such ideal conditions as its explanans. ${ }^{13}$

This is not to deny that it is possible to hold a 'transcendentalist' but not an idealist position (and vice versa), or that it is possible to hold either position in a generally 'Kantian' or 'Husserlian' way (i.e., in a way that is informed by Kant or Husserl, or both). It is to affirm that Kant's and Husserl's transcendental idealisms

\footnotetext{
${ }^{9}$ This means that it is possible to 'naturalize' phenomenology but impossible to do so without going against Husserl on this specific point, which is unproblematic as long as one is aware of it.

${ }^{10}$ The list of 'transcendentalists' in this very broad sense could be surprisingly long and may include thinkers as varied as Plato, Karl Marx, Martin Heidegger, Michel Foucault, Judith Butler, Mark Rowlands and many others (whether it actually does is a contentious issue).

${ }^{11}$ This explains to some extent Kant's and Husserl's frustration with the persistence of the idealism charges leveled against them. It also explains why the much more recent label of 'anti-realism' is, to put it mildly, misleading.

${ }^{12}$ The list of idealists in this very broad sense is known to be long but is likely to exclude thinkers as varied as Plato, Karl Marx, Martin Heidegger, Michel Foucault, Judith Butler, Mark Rowlands and many others (whether it actually does is a contentious issue).

${ }^{13}$ This explains to some extent the persistence of the idealism charges leveled against Kant and Husserl. It also explains why the much more recent label of 'anti-realism' appears so appropriate.
} 
essentially involve both positions. However, this agreement, as I have presented it here, depends on further agreements, which are tacitly assumed and need to be made explicit. The first is that both Kant and Husserl consider 'philosophical' to be opposed to 'empirical' (or, to use Husserl's term, 'natural'). This reflects their shared belief that philosophy is concerned with (not only analytic) a priori judgments, and thus with a 'rigorous science' that cannot be reduced to formal logic or empirical psychology (cf. Hua VII, p. 287).

The second is that both Kant and Husserl consider 'ideal' to be opposed to 'objective', and hence as subjective. In this regard, they are both post-Cartesians (rather than, for example, Platonists) and firmly rooted in a specifically modern paradigm; but they are also post-empiricists in that they always consider the subject in its relation to the world (and not as, for example, a soul with innate ideas, or a divine intellect). What makes Kant's and Husserl's transcendental idealist philosophies distinctive is the combination of these two assumptions. Only in this combination lies the so-called 'Copernican revolution', which maintains that (1) a priori truths about the world are intelligible, but that they are (2) only in relation to a subjectivity that experiences the world. ${ }^{14}$ However, one further qualification is needed.

None of the shared 'assumptions' are dogmatically adopted by either Kant or Husserl as assumptions. Instead, they are critically adopted as working hypotheses (Fincham, 2011, p. 226). ${ }^{15}$ These are, for Kant, in need of final proof (his transcendental deduction), and, for Husserl, in need of infinite demonstration in evidence (the continuous project of transcendental phenomenology). Of these hypotheses, only the commitment to realism is substantial. It can be considered the most fundamental insofar as both Kant and Husserl think of this commitment as commonsensical or 'natural'. The task of critical philosophy, as they see it, is to 'scientifically' justify (Kant) or clarify (Husserl) realism, but not to skeptically consider it as actually 'up for grabs'. ${ }^{16}$

The anti-representationalism operating in both Kant's and Husserl's accounts of sensible, or intuitive representations is in each case the result of an analysis that is based on the shared working hypotheses just laid out, that is, on 'transcendental idealism'. What is often overlooked is that the different formulations of transcendental idealism given by Kant or Husserl are to be read not as doctrines (which one

\footnotetext{
${ }^{14}$ Kant's presentation of the Copernican revolution already implies this since, according to the analogy he draws, the subject in question is an 'observing', i.e., experiencing subject, not a subject whose relation to the world first needs be established.

${ }^{15}$ Note that Kant calls the Copernican revolution 'an experiment' (KrV, B XVI, XVIII).

${ }^{16}$ On the role of common sense in Kant see Ameriks, 2000.-This explains why Kant sees no need for a separate 'refutation of idealism' in the first edition of the Critique of Pure Reason but only adds it in the second edition, in response to charges of idealism leveled against him after the publication of the first edition. Both Kant and Husserl claim that although we could be wrong individually about any judgment in which, on the basis of perception, we attribute existence to a thing; we could not be wrong collectively about the existence of perceivable things in general. Even Husserl, who does not attempt and does not consider possible a 'refutation of idealism' in the form of a logical argument, simply considers the evidence for their (collective) existence so overwhelming that he deems the skeptical position 'counter-sensical' (widersinnig).
} 
assents to when one, so to speak, decides to become a transcendental idealist), ${ }^{17}$ but as explanations or clarifications that result from transcendental idealism as a working hypothesis. After all, as Lucy Allais has pointed out, to "distinguish between things as they appear to us and things as they are in themselves is not necessarily idealist, neither is arguing that we cannot have knowledge of mind-independent reality" (Allais, 2004, p. 669). And, I would like to add, either view can be held without taking a transcendental stance.

If the results of transcendental idealism (understood as a critical hypothesis) are read in reference to a transcendental stance from whose perspective alone they are rendered valid, then one and the same analysis may include different, even conflicting results, which are compossible as long as one distinguishes between transcendental and empirical levels of analysis. Thus there is nothing self-contradictory in the fact that Kant's transcendental idealism involves and indeed justifies the claim that, empirically speaking, things themselves appear and that, empirically speaking, we can have knowledge of mind-independent reality (as he himself points out, e.g. see KrV, A 29/B 45). At the same time, two analyses that adopt the critical hypothesis of transcendental idealism may have very different, even conflicting results if they employ very different methods. Thus there is nothing problematic in the fact that Husserl's transcendental idealism, in contradiction to Kant's, involves the claim that things themselves appear and that we can have knowledge of mind-independent reality (under the methodological proviso that this is evident only 'under the phenomenological and eidetic variations').

I consider the parallels I identify above between Kant and Husserl as the most essential. There are many others to be found in the details of their analyses (e.g., on time and space, on anti-representationalism, on the centrality of syntheses for consciousness), which may be called 'derivative', insofar as they result from concrete philosophical investigations that otherwise follow very different methods and are thus given very different explanations of clarifications. The essential agreements that I see, with the possible exception of their shared commitment to realism, may be called 'formal' insofar as Kant and Husserl fill these agreements out in substantially different ways, according to their respective methods.

\subsection{Some Essential Disagreements Concerning Method}

The most important disagreement between Kant and Husserl is methodological. It concerns the legitimate justification of a priori claims in general, and of philosophical claims in particular. For Kant, the justification of a priori claims is the business of "rational cognition" (KrV, A 837/B 865). Pure philosophy is "cognition from pure reason" (KrV, A 840/B 868) and legitimizes its claims "from concepts" (KrV, A 844/B 872). Although he insists that cognition always requires contributions from

\footnotetext{
${ }^{17}$ This might be more obvious in the case of Husserl but it is helpful to recall that Kant does not want his 'critique' understood as a doctrine either (cf. KrV, A 11 f./B 25 f.).
} 
both sensibility and understanding, he believes that the necessity and universality of philosophical a priori claims can only be recognized by means of rational thinking, which he, of course, considers distinct from any mode of intuiting. In fact, he defines an a priori judgment as "a proposition such that in thinking it we think at the same time its necessity" and "strict universality", which "experience never provides" (KrV, B 3; my italics).

Husserl is opposed to the intellectualism of Kant's method. Instead, he develops a new 'phenomenological' method, based on the idea that even philosophical a priori truths cannot be justified by argument (i.e., 'in thought') alone, but must be brought to evidence in an 'intellectual seeing' (Hua III/1, p. 317), e.g., an eidetic 'seeing' in which essential relations and invariances are grasped directly. By this criterion, philosophical arguments (Kant's included) are 'empty' and lacking in justificatory power unless they can be supported by a 'fulfilling' experience, by 'evidence' of an appropriate kind. Nothing is 'proven' unless and until it is 'shown' with evidence, which Husserl describes "in an extremely broad sense" as an original “"experiencing' of something that is, and is thus" (Hua I, p. 52; see Hua III/1, p. 1). In line with Wundt's interpretation that " "evidence' is only a translation of 'intuitiveness [Anschaulichkeit]"' (Wundt, 1906, p. 78), Husserl thus adopts an 'extremely broad sense' of intuition, which is meant to capture this notion of evidence. On the basis of this very broad sense of intuition, Husserl's phenomenology can be understood, albeit in phenomenological senses of the expressions, as philosophical 'intuitionism', as 'radical empiricism' (Solomon, 2001, p. 146), or as 'genuine positivism' (Hua III/1, § 20). It uses a justificatory principle - the "principle of principles" (Hua III/1, § 24) - that is obviously irreconcilable with Kant's, with the result that, from Husserl's perspective, Kant's philosophy is replete with illegitimate claims, and vice versa.

There are too many further disagreements that follow from this for them to be listed here (or anywhere). However, many of them become intelligible in their inevitability if one keeps the fundamental methodological disagreement between Kant and Husserl in mind. To illustrate this, I now return to the anti-representationalist accounts of intuitive representation laid out in the first section. Despite Kant's and Husserl's shared realism, some irreconcilable and inevitable differences can easily be identified. For example, it is integral to Kant's account that the transcendental distinction between cognizable appearances and merely thinkable things in themselves be upheld (for reasons relating to Kant's moral philosophy and his conceptions of God and faith). Within the framework of Husserl's phenomenology, on the contrary, this same distinction is untenable (because it can only be thought and thus lacks any phenomenological evidence), not only on the level of empirical analysis, but also on the level of transcendental analysis. For Husserl, it is simply "nonsense [Unsinn] to base the being of a thing on a being that is in principle un-experiencable [unerfahrbar]" (Hua XXXVI, p. 32); it is an expression of "a dogmatic objectivism that deals with transcendent metaphysical suppositions" (Hua VII, p. 369). Hence, he regards all appearances as the things themselves appearing (Hua III/1, § 43).

Further, Kant is forced, by his own methodological and justificatory principles, to present a transcendental argument for his anti-representationalist account, which 
is therefore inseparable from his notion of a transcendental synthesis of the imagination. It, and only it, explains that and why perceptions are always determinable by concepts, despite the fact that, for Kant, sensibility and understanding are distinct stems of cognition. Since this synthesis is required (nötig), it is necessary (notwendig). Husserl, as is well known, rejects this argument, at least initially (under the influence of Friedrich Albert Lange's materialist Kant interpretation), and also rejects the very idea of such a 'creative (schöpferische) synthesis' (Hua XII, p. 39 ff.). Only when it is cut from its origin in Kant's faculty-psychology - in Husserl's eyes, yet another illegitimate 'mythical' construct (Hua VII, p. 401) that betrays Kant's psychologism (Hua VII, p. 402) and anthropologism (Hua III/1, § 150) - and described in phenomenological analysis, can it be considered legitimate according to Husserlian criteria. Then, without any need for a reference to some power of imagination (Einbildungskraft), it is understood as the generic term for constitutions of sense (Kern, 1964, pp. 262 f.). These, in their passive and active modes, collectively constitute rationality, or 'understanding' in a broad Husserlian sense, which includes both sensible and intellectual consciousness in the Kantian sense of the terms. In the light of these radically changed conditions, Husserl refers to the idea of a transcendental synthesis of the imagination as Kant's idea of a 'doubly functioning understanding (doppelt fungierenden Verstand)' (Hua VI, $\S \S 25$ and 28).

Doing away with Kant's method and justificatory criteria, Husserl proceeds in what Kant would have considered an empirical fashion. Husserl, however, rejects the Kantian idea that a priori truths are ultimately based on a priori forms of cognition and that the Copernican revolution therefore leads back to purely formal conditions in the thinking subject. Instead, he legitimizes his claims with the phenomenological reduction, which he understands as "the Copernican Turn, enacted in its radical form" (Hua XXXIV, p. 55; see Hua VII, p. 254), and with the eidetic variation, which enables Husserl to identify the essential (a priori) features of a phenomenon. This leads, of course, to a fundamentally different conception of the a priori. Hence, Husserl's anti-representationalist account describes the essential features of sense-formations in which (perceptual) transcendent objects are constituted as 'them themselves', albeit always only in relation to (perceiving) transcendental consciousness. This renders these objects mind-dependent in the (Husserlian) sense that they essentially require subjectivity as their correlate, not in the (Kantian) sense that their formal a priori features have their origin in subjective a priori forms of cognition.

\section{Conclusion}

Many defenses of Husserl's anti-representational realism have been published, especially (but not only) recently (Ameriks, 1977; Crowell, 2001; Drummond, 1990; Luft, 2011; Moran, 2004; Zahavi, 2008, 2004 et al.). In a parallel development, there is also an increasing number of defenses of a realist, anti-representationalist reading of Kant, especially (but not only) recently (Allais, 2011, 2007, 2004; Alli- 
son, 2004; Ameriks, 2000, 1992; Collins, 1992 et al.). What we are seeing is the gradual realisation that realism is indeed, as both Kant and Husserl claimed, not only reconcilable with transcendental idealism, but its original task. Zahavi is right to suggest that "a useful way to interpret transcendental idealism is by defining it negatively as an anti-representationalist criticism of metaphysical realism" (Zahavi, 2008, p. 364). However, as Zahavi admits, this is only, as he calls it, a 'deflationary' interpretation of transcendental idealism, and it is so broad that it fails to say much about what is characteristic of Kant's or Husserl's transcendental idealism in particular.

Here the comparison between the two alternative transcendental idealisms is instructive. It allows us to distinguish essential and non-essential features of transcendental idealist approaches. This helps us to avoid quick equivocations and misinterpretations borrowed from different transcendental idealisms. Moreover, it enables us to make explicit the specific conditions and implications of different versions thereof. Ultimately, it frees us to critically investigate and perhaps even conceive of further alternative possibilities for transcendental philosophy in general or transcendental idealism in particular. ${ }^{18}$

\footnotetext{
${ }^{18}$ The completion of this article was made possible by a generous research leave granted by University College Cork.
} 